\title{
Effect of Oxygen Vacancy Concentration on the Photocatalytic Hydrogen Evolution Performance of Anatase TiO2: DFT and Experimental Studies
}

\section{Shufang Jia}

Taiyuan University of Technology School of Materials Science and Engineering Jiaqi Gao

Taiyuan University of Technology School of Materials Science and Engineering

\section{Qianqian Shen}

Key Laboratory of Science and Engineering in Advanced Materials (Taiyuan University of Technology)

\section{Jinbo Xue}

Key Laboratory of Interface Science and Engineering in Advanced Materials (Taiyuan University of Technology)

\section{Zhuxia Zhang}

Key Laboratory of Interface Science and Engineering in Advanced Materials(Taiyuan University of Technology)

\section{Xuguang Liu}

Taiyuan University of Technology School of Materials Science and Engineering

Husheng Jia ( $\nabla_{\text {jia_husheng@126.com ) }}$

Taiyuan University of Technology School of Materials Science and Engineering https://orcid.org/00000001-8257-8874

\section{Research Article}

Keywords: Oxygen vacancy, First-principles calculation, Anatase TiO2 (101), Catalytic activity

Posted Date: March 12th, 2021

DOI: https://doi.org/10.21203/rs.3.rs-282876/v1

License: (c) (i) This work is licensed under a Creative Commons Attribution 4.0 International License. Read Full License

Version of Record: A version of this preprint was published at Journal of Materials Science: Materials in Electronics on April 18th, 2021. See the published version at https://doi.org/10.1007/s10854-021-059155 . 


\section{Abstract}

Oxygen vacancies (OVs) are important for changing the geometric and electronic structure as well as the chemical properties of anatase $\mathrm{TiO}_{2}$. In this work, we performed a DFT calculation on the electronic structure and catalytic performance of anatase $\mathrm{TiO}_{2}$ (101) with different numbers of OVs. A comparison of the measured XRD results with the simulated ones of $\mathrm{TiO}_{2}$ demonstrates that OVs can cause changes in the crystal structure. The changes in the electronic structure (Mulliken charges, band structure, and partial density of states) and water splitting on $\mathrm{TiO}_{2}$ (101) surfaces were investigated as a function of oxygen vacancy concentration. The results show that the introduction of oxygen vacancy forms impurity levels below the conduction band of Ti $3 \mathrm{~d}$ orbitals, and electrons can gradually transit from VB to CB through the impurity levels. However, when oxygen vacancy concentration is too high, the maximum electron transition energy increases and the promotion effect of oxygen vacancy on water splitting is weakened. This work would provide more enlightenment and information for the design of defective $\mathrm{TiO}_{2}$ with higher photocatalytic activity.

\section{Introduction}

The increasing consumption of fossil energy has caused serious energy crisis and environmental problems. Hydrogen as a renewable and environmentally friendly new energy has attracted great attention of scientific community [1]. In 1972, Fujishima and Honda found hydrogen production from $\mathrm{H}_{2} \mathrm{O}$ splitting on a $\mathrm{TiO}_{2}$ photoelectrode [2], inspiring much concern on semiconductor photocatalytic materials from scientists in the scientific field. Solar energy is a kind of renewable green energy, and its use for semiconductor-based photocatalytic water splitting to produce hydrogen has been considered as one of the most important solutions to world energy crisis [3]. Titanium dioxide $\left(\mathrm{TiO}_{2}\right)$ is perhaps one of the most important materials used as photocatalyst for hydrogen generation owing to its excellent properties such as superior photostability, non-toxicity, abundant reserves, and low cost [4-6]. Two common crystal types of $\mathrm{TiO}_{2}$ are anatase and rutile, which have high catalytic activity and stability. However, $\mathrm{TiO}_{2}$ is a wide band gap semiconductor (rutile: $3.0 \mathrm{eV}$; anatase: $3.2 \mathrm{eV}$ ), and only absorbs ultraviolet light that accounts only for about $5 \%$ of the solar energy. Therefore, its solar energy utilization efficiency is very low, making it impossible for large-scale industrial applications [7, 8]. Hence, improving the optical sensitivity and activity of $\mathrm{TiO}_{2}$ in the visible light region has been explored with strategies based on doping, ion implantation, metal loading, and composite semiconductors $[9,10]$. In recent years, self-doped oxygen vacancy has been extensively studied experimentally and theoretically. This doping method features not only low cost, but also the ease in preparation and high effectiveness [11, 12].

The research results have shown that oxygen vacancies in $\mathrm{TiO}_{2}$ are preferential active sites for molecular adsorption and dissociation, in addition to being traps for photoexcited charged carriers [13,14]. Zuo et al. [15] reported a one-step method to synthesize $\mathrm{Ti}^{3+}$-doped $\mathrm{TiO}_{2}$. Both theoretical calculations and experimental results confirmed that the introduction of $\mathrm{Ti}^{3+}$ extends the photocatalytic activity from ultraviolet to visible light. In our previous work, black $\mathrm{TiO}_{2}$ nanotubes with oxygen vacancies (OVs) were 
prepared, and through experimental characterizations, the enhancement in photocatalytic performance by the introduction of OVs was proved [16]. The excess electrons and $\mathrm{Ti}^{3+}$ sites generated by OVs affect the adsorption and reaction of adsorbate on $\mathrm{TiO}_{2}$ surface, and significantly improve its photocatalytic performance [17]. Hinuma et al. [18] used density functional theory (DFT) to calculate $E_{\text {Ovac }}$ on various semiconductor oxide surfaces at the same computational level, and investigated the adsorption of small molecules on anoxic surfaces. The results showed that their adsorption energy and adsorption mode are strongly dependent on $E_{\text {Ovac. }}$ Moreover, Kong et al. [19] reported that the concentration of bulk OVs in $\mathrm{TiO}_{2}$ can adjust the photocatalytic efficiency. Wei et al. [20] investigated the adsorption properties of $\mathrm{H}_{2} \mathrm{~S}$ on rutile $\mathrm{TiO}_{2}(110)$ surface with different $\mathrm{OV}$ coverage. Since oxygen vacancy has an important effect on photocatalytic activity, it is of great significance to introduce oxygen vacancy in a controlled manner.

In the past, a large number of experiments and theoretical calculations have mainly focused on the properties of rutile $\mathrm{TiO}_{2}(110)$, including those from the introduction of OVs and for the interaction with water [21-23]. Recently, some studies have shown that anatase has a higher photocatalytic activity than rutile, so the most stable (101) surface in anatase has recently received a lot of attention [24-26]. Therefore, in this work, we investigated the surface properties of anatase $\mathrm{TiO}_{2}(101)$ surface at different OV concentration $(0 / 8,1 / 8,2 / 8,3 / 8$ monolayer) and their effect on the surface adsorption and dissociation of water.

In persent study we combined the experimental and theoretical aspects to investigate the influence of OV concentration on the electronic structure and catalytic performance of anatase $\mathrm{TiO}_{2}$ (101). First, the XRD patterns of $\mathrm{TiO}_{2}$ crystals with different $\mathrm{OV}$ concentrations were simulated and compared with the experimental XRD patterns of $\mathrm{TiO}_{2}$ samples to explore the relationship between crystalline phase and $\mathrm{OV}_{\mathrm{S} \square}$ Second, a stable $\mathrm{TiO}_{2}$ (101) surface was selected to examine the effect of OV concentrations on anatase (101) geometry and electronic structure. Finally, by calculating the dissociation transition state of $\mathrm{H}_{2} \mathrm{O}$ on the surface of $\mathrm{TiO}_{2}(101)$, the influence of $\mathrm{OV}$ concentration on water dissociation was analyzed. The results of DFT calculation show that moderate OV concentration can improve the transition ability of electrons. This work is expected to have a theoretical guidance for the use of anatase $\mathrm{TiO}_{2}(101)$ surface as a catalyst for the photolysis of water to produce hydrogen.

\section{Experimental And Computational Details 2.1 Experimental Details}

$\mathrm{TiO}_{2}$ nanotube arrays were prepared by electrochemical anodic oxidation. Titanium sheets were ultrasonically cleaned with acetone, ethanol, and deionized water, and then anodized in $100 \mathrm{~mL}$ of $\mathrm{NH}_{4} \mathrm{~F}$ ethylene glycol (EG) solution ( $0.47 \mathrm{~g}$ of $\mathrm{NH}_{4} \mathrm{~F}, 98 \mathrm{~mL}$ of $\mathrm{EG}$, and $2 \mathrm{~mL}$ of deionized water) at $50 \mathrm{~V}$ for $1 \mathrm{~h}$ at room temperature with a platinum plate as counter electrode. The as-anodized samples were thoroughly cleaned with deionized water, wrapped with aluminum powder and annealed at $300^{\circ} \mathrm{C}, 450^{\circ} \mathrm{C}$ 
and $600^{\circ} \mathrm{C}$ separately in argon for $2 \mathrm{~h}$ with a heating rate of $2^{\circ} \mathrm{C} / \mathrm{min}$, denoted as $\mathrm{B}-\mathrm{TiO}_{2}-300, \mathrm{~B}-\mathrm{TiO}_{2}-450$, and $\mathrm{B}-\mathrm{TiO}_{2}-600$, respectively. For comparison, $\mathrm{TiO}_{2}$ nanotube arrays were annealed in air at $450^{\circ} \mathrm{C}$ for $2 \mathrm{~h}$ to give a control sample without oxygen vacancies, which is denoted as $\mathrm{TiO}_{2}$-Air. The phase structure of samples was characterized by employing X-ray diffraction (XRD) with Cu Ka irradiation $(\lambda=1.5406 \AA)$ operating at $40 \mathrm{kV}$ tube voltage and $30 \mathrm{~mA}$ tube current. The diffraction patterns between $20^{\circ}$ and $80^{\circ}$ (20) were collected in a step of $0.02^{\circ}$. JEOL JES-FA200 EPR spectrometer was used to record electron paramagnetic resonance (EPR) spectra at room temperature. UV-vis diffused reflectance spectroscopy (DRS) results were collected on a PerkinElmer Lambda 950 spectrophotometer in wavelength range of $300-800 \mathrm{~nm}$.

Hydrogen evolution tests of two pieces of black $\mathrm{TiO}_{2}$ nanotube arrays were carried out in a $100 \mathrm{~mL}$ photochemical quartz cell containing $100 \mathrm{~mL}$ of deionized water, and $20 \mathrm{~mL}$ of methanol as the sacrificial reagent. Then, $66 \mu \mathrm{L}$ of $\mathrm{H}_{2} \mathrm{PtCl}_{6}(15 \mathrm{mg} / \mathrm{mL})$ was injected into the mixed solution. The suspensions were maintained strictly at $3^{\circ} \mathrm{C}$ by re-circulating cooling water system. The system was deaerated by bubbling $\mathrm{N}_{2}$ into the solution for $20 \mathrm{~min}$ before light irradiation. The excitation light source was a $300 \mathrm{~W}$ Xenon lamp equipped with a UV-cutoff filter (> $420 \mathrm{~nm})$, and the light intensity was measured to be $100 \mathrm{~mW} / \mathrm{cm}^{2}$. The reaction system was irradiated for about 5 hours, and $\mathrm{H}_{2}$ amount was measured by an 8890 Gas Chromatograph System equipped with a thermal conductivity detector (TCD).

\subsection{Computational Method and Models}

All the calculations in this work were completed by using the Cambridge Serial Total Energy Package (CASTEP) module of Materials Studio (MS). The plane-wave ultrasoft pseudopotential based on density functional theory (DFT) was adopted, and the exchange-related energy was calculated by the PBE functional under Generalized Gradient Approximation (GGA) [27]. Because conventional DFT calculations based on the local density approximation cannot truly describe the electronic correlation in transition metal oxides, DFT + U method was introduced to evaluate the on-site coulombic interactions in the localized d orbital and exchange interactions, by adding an effective Hubbard-U parameter to express the repulsion between electrons on the same orbital [28]. In our calculations, the value of $U$ parameter was determined to be $3.5 \mathrm{eV}$ for Ti atom [29,30]. The valence electron configurations are $3 \mathrm{~d}^{2} 4 \mathrm{~s}^{2}$ for Ti and $2 s^{2} 2 p^{4}$ for 0 , respectively. The energy cutoff for the plane wave basis set was selected as $380 \mathrm{eV}$, and a $3 \times 3 \times 1$ Monkhorst-Pack k-point grid was used to integrate the Brillouin zone. The convergence criteria of energy, maximum force, maximum stress, and maximum displacement are $1 \times 10^{-5} \mathrm{eV} /$ atom, $0.03 \mathrm{eV} / \AA$, $0.05 \mathrm{GPa}$, and $0.001 \AA$, respectively. The optimized anatase $\mathrm{TiO}_{2}$ lattice parameters are $\mathrm{a}=\mathrm{b}=3.79 \AA$ and $c=9.77 \AA$, which are consistent with the previous experimental and theoretical results [31-33].

Table 1 Formation energy of OVs at different positions 


\begin{tabular}{ccc}
\hline Model & OVs site & $E_{\text {Ovf }} / \mathrm{eV}$ \\
\hline 1/8ML & 1 & 4.69 \\
\hline $2 / 8 \mathrm{ML}$ & $1-2$ & 4.93 \\
& $1-6$ & 4.88 \\
& $1-7$ & 4.86 \\
\hline 3/8ML & $1-2-7$ & 5.04 \\
& $1-4-7$ & 5.02 \\
\hline
\end{tabular}

In this work, a $(1 \times 4)$ anatase $(101)$ surface supercell was used as the slab model with three $0-\mathrm{Ti}-0$ layers, and the underlying $\mathrm{O}-\mathrm{Ti}-\mathrm{O}$ layer was fixed to simulate the bulk atomic structure, as shown in Fig. 1. In order to avoid the interaction between adjacent surfaces, a $20 \AA$ vacuum layer was installed for all systems. This structural model has proved to be very reliable in many studies [34,35]. On the basis of this model, the anatase $\mathrm{TiO}_{2}$ (101) surface models with different concentration of OVs $(0 / 8,1 / 8,2 / 8,3 / 8 \mathrm{ML})$ were constructed by removing the two-fold coordinated $\mathrm{O}$ atom (one, two, three), and the removed $\mathrm{O}$ atoms denoted as OVs are marked with black circles, as shown in Fig. 2a-c. By calculating the formation energy of oxygen vacancy at different positions, as shown in Table 1, the models with less vacancy formation energy were selected for calculation, as shown in Fig. 2. The OV formation energy $\left(E_{\text {ovf }}\right)$ at each position was calculated by the following formula:

$$
E_{\text {ovf }}=E_{\text {tot }(\text { defect })}-E_{\text {tot }(\text { perfect })}+n_{0} \mu_{0}
$$

where, $E_{\mathrm{tot}(\text { perfect) }}$ and $E_{\mathrm{tot}(\text { defect) }}$ are the total energy of perfect anatase $\mathrm{TiO}_{2}$ (101) surface and anatase $\mathrm{TiO}_{2}$ (101) surface with oxygen vacancies, respectively, $\mu_{0}$ thechemical potential of oxygen atom, and $n_{0}$

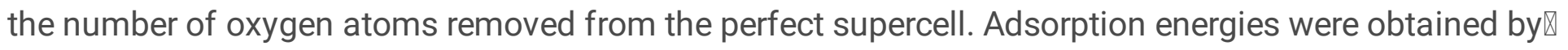

$$
E_{\text {ads }}=E_{\text {surf }-\mathrm{H}_{2} \mathrm{O}}-\left(E_{\text {surf }}+E_{\mathrm{H}_{2} \mathrm{O}}\right)
$$

where, $E_{\text {surf-H2O }}, E_{\text {surf, }}$ and $E_{\mathrm{H} 2 \mathrm{O}}$ are the total energies calculated for the slab with adsorbate, the clean stoichiometric slab, and the adsorbate in gas phase, respectively.

Since it is difficult to evaluate the solvent effect of a real liquid reaction in the solid surface system, during the adsorption and dissociation of water molecule, we only consider the adsorption and decomposition behavior of water molecules on the surface of defective anatase $\mathrm{TiO}_{2}(101)$ in the case of no solvent (i.e. in the gas environment). The most stable adsorption and dissociation configurations of water molecules on the surface were optimized, and these two configurations were set as the initial state (reactant) and final state (product), respectively. Complete linear synchronous transit (LST) and quadratic synchronous transit (QST) approaches were chosen to search for transition states, and then the nudged elastic band (NEB) method was used to determine the transition state on the minimum reaction energy 
path [36-38]. According to the calculated adsorption energy of these states, the reaction activity and energy of water splitting reaction on the surface of anatase $\mathrm{TiO}_{2}(101)$ with different oxygen vacancy concentration were analyzed.

\section{Results And Discussion}

\subsection{Structural characteristics of anatase $\mathrm{TiO}_{2}$ catalysts}

Black $\mathrm{TiO}_{2}$ nanotube arrays were prepared by anodic oxidation and aluminum powder reduction. The crystallinity and phase composition of black $\mathrm{TiO}_{2}$ nanotube arrays after annealing at different temperatures were characterized by X-ray diffraction (XRD), and the XRD patterns of the prepared $\mathrm{TiO}_{2}$

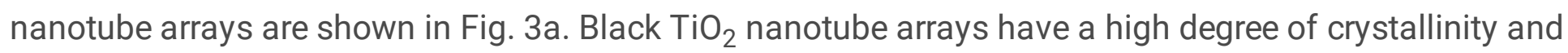
characteristic diffraction peaks similar to anatase $\mathrm{TiO}_{2}$, corresponding to the reflective crystal planes of (101), (004), (105), (204), (116), (220), and (301). In the measured XRD patterns in Fig. 3a, a new diffraction peak appears at $2 \theta 33.8^{\circ}$, and the higher the annealing temperature, the higher the intensity of the peak. The reason may be that a large amount of charge generated by the oxygen vacancies causes the charge in the valence of cation, so that anatase $\mathrm{TiO}_{2}$ is reduced to form a new stable phase [40]. In order to further prove that the changes in the surface structure of black $\mathrm{TiO}_{2}$ nanotube arrays are caused by oxygen vacancies, electron paramagnetic resonance (EPR) was used to detect the presence of oxygen vacancies. The $\mathrm{g}$ factor of the signal is equal to 1.994, which corresponds to the surface oxygen vacancies, as shown in Fig. 3b [41, 42]. With the increase of aluminothermic reduction temperature, the intensity of the EPR signal becomes stronger, suggesting the increase of oxygen vacancy concentration on the surface of black $\mathrm{TiO}_{2}$ nanotube arrays. This finding is consistent with the conclusion obtained from XRD results.

For materials with known structures, it is a commonly used method to calculate theoretical XRD patterns by software[43]. In this section, XRD patterns were simulated by the Reflex software package from Materials Studio (MS) according to the crystal structure. Therefore, a 48 -atom $2 \times 2 \times 1$ supercell $\left(\mathrm{Ti}_{16} \mathrm{O}_{32}\right)$ was used to simulate the XRD patterns of anatase $\mathrm{TiO}_{2}$ with different numbers of OVs, and compare them with the experimental XRD patterns of $\mathrm{TiO}_{2}$ samples. As shown in Fig. $3 \mathrm{c}, \mathrm{a} \mathrm{Ti}_{16} \mathrm{O}_{32}$ model with 2, 4, or 6 OVs was constructed to form OV concentration of $1 / 16,1 / 8$, and $3 / 16$, respectively. As shown in Fig. 3d, in the simulated XRD patterns of anatase $\mathrm{TiO}_{2}$ crystals containing different numbers of OVs, a new diffraction peak also appears at $33.8^{\circ}$. As the OV concentration increases, the peak intensity at $33.8^{\circ}$ increases proportionally. These results indicate that there are different numbers of OVs in black $\mathrm{TiO}_{2}$ nanotube arrays, as also shown in the XRD patterns in Fig. 3a. Therefore, the anatase $\mathrm{TiO}_{2}$ crystal (Fig. 3c) can represent the structure of $\mathrm{TiO}_{2}$ obtained at different aluminothermic temperatures. Consequently, computational simulation was adopted to explore the properties of anatase $\mathrm{TiO}_{2}$ with different $\mathrm{OV}$ concentration, and evaluate the difference in its electronic structure from a theoretical perspective. 
3.2 Influences of $\mathrm{OV}_{\mathrm{S}}$ on the geometrical and electronic structure and optical properties of anatase $\mathrm{TiO}_{2}$ (101)

\subsubsection{Geometry structure}

The introduction of oxygen vacancy on the surface of $\mathrm{TiO}_{2}(101)$ causes lattice distortion of its surface structure. The original $\mathrm{Ti}_{6 \mathrm{c}}$ and $\mathrm{Ti}_{5 \mathrm{c}}$ atoms bonded to the $\mathrm{O}_{2 \mathrm{c}}$ atoms at the vacancies become 5 - and 4coordinated, denoted as $\mathrm{Ti}_{\mathrm{V}-5 \mathrm{c}}$ and $\mathrm{Ti}_{\mathrm{V}-4 \mathrm{c}}$, respectively. On the optimized defect surface, the removal of $\mathrm{O}$ atoms from the surface of lattice strengthens the relationship between adjacent Ti atoms and other adjacent $\mathrm{O}$ atoms, and shortens the length of $\mathrm{Ti}-\mathrm{O}$ bonds. The calculated results are consistent with the experimental ones [42].

By comparing the optimized surface structures, we conducted a detailed analysis on the same position of the surface, as shown in Fig. 4, and found that different concentration of oxygen vacancy causes different degree of lattice distortion of the surface structure. The $\mathrm{O}_{3 \mathrm{c}}$ on the surface of $1 / 8 \mathrm{ML}$ oxygen vacancy relaxes upwards by $0.23 \AA$, and $\mathrm{Ti}_{\mathrm{v}-5 \mathrm{c}}$ and $\mathrm{Ti}_{\mathrm{v}-4 \mathrm{c}}$ relax inwardly by 0.32 and $0.28 \AA$, respectively, which results in the change in $\mathrm{Ti}_{v-5 c}-0-\mathrm{Ti}_{\mathrm{v}-4 \mathrm{c}}$ on the surface structure from $94.16^{\circ}$ to $130.21^{\circ}$. The $\mathrm{O}_{3 \mathrm{c}}$ on the surface of $2 / 8 \mathrm{ML}$ oxygen vacancies relaxes upwards by $0.29 \AA$, and $\mathrm{Ti}_{\mathrm{v}-5 \mathrm{c}}$ and $\mathrm{Ti}_{\mathrm{v}-4 \mathrm{c}}$ relax inwardly by 0.32 and $0.26 \AA$, respectively, which results in the enlargement of $\mathrm{Ti}_{\mathrm{v}-5 \mathrm{c}}-0-\mathrm{Ti}_{\mathrm{v}-4 \mathrm{c}}$ on the surface structure from $94.16^{\circ}$ to $134.56^{\circ}$. The $O_{3 c}$ on the surface of the $3 / 8 \mathrm{ML}$ oxygen vacancies relaxes upwards by $0.27 \AA$, and $\mathrm{Ti}_{\mathrm{v}-5 \mathrm{c}}$ and $\mathrm{Ti}_{\mathrm{v}-4 \mathrm{c}}$ relax inwardly by 0.34 and $0.22 \AA$, respectively, which results in the increase in $\mathrm{Ti}_{\mathrm{v}-5 \mathrm{c}}-\mathrm{O}-\mathrm{Ti}_{\mathrm{v}-4 \mathrm{c}}$ on the surface structure from $94.16^{\circ}$ to $133.28^{\circ}$. Through the research on the adsorption of $\mathrm{H}_{2} \mathrm{O}$ on the surface in the following section, it is found that the increase in lattice distortion can enhance the adsorption of $\mathrm{H}_{2} \mathrm{O}$ on the surfaces.

\subsubsection{Electronic structure}

In order to understand the effects of OV concentration on the electronic structure of anatase $\mathrm{TiO}_{2}(101)$ surface, the Mulliken charge, differential charge density, band structure, and partial density of states (PDOS) as a function of OV concentration were calculated. Table 2 shows the average Mulliken charges of $\mathrm{Ti}$ atoms on the surface structure of anatase $\mathrm{TiO}_{2}(101)$. It can be found that the Mulliken charges of $\mathrm{Ti}$ atoms decrease with the increase of oxygen vacancy concentration, which is due to the redistribution of excess electrons generated by oxygen vacancy in the position of adjacent $\mathrm{Ti}$ atoms. The effect of average Mulliken charge on anatase $\mathrm{TiO}_{2}(101)$ is also shown in the differential charge density diagram of anatase $\mathrm{TiO}_{2}$ (101) with OVs. As shown in Fig. 5, the charge density of $\mathrm{Ti}$ atoms on the surface around OVs is increased significantly. It is worth noting that when the number of OVs increases to 3 , the charge density of $\mathrm{Ti}$ atoms next to the OVs is relatively weakened. 
Table 2

Average Mulliken charge of $\mathrm{TiO}_{2}(101)$ with OVs

\begin{tabular}{|cll|}
\hline Model & Total Ti atoms & Surface Ti atoms \\
\hline $0 / 8 \mathrm{ML}$ & 1.395 & 1.390 \\
\hline $1 / 8 \mathrm{ML}$ & 1.328 & 1.316 \\
\hline $2 / 8 \mathrm{ML}$ & 1.317 & 1.296 \\
\hline $3 / 8 \mathrm{ML}$ & 1.307 & 1.273 \\
\hline
\end{tabular}

In order to further analyze the influence of OV concentration on the electronic structure of anatase $\mathrm{TiO}_{2}$ (101), the band structures and density of states of the four different models $(0 / 8,1 / 8,2 / 8,3 / 8 \mathrm{ML})$ were calculated on the basis of structural optimization. The comparison of our results with the previous research results of the electronic properties of the defect anatase (101) surface is summarized in Table 3.

Table 3

Band gaps $\left(E_{\mathrm{g}}\right)$ of defect anatase (101) surface under varying computational parameters

\begin{tabular}{|llll|}
\hline Anatase (101) & $E_{\mathrm{g}}(\mathrm{eV})$ & Method & Reference \\
\hline $\mathrm{O}_{\mathrm{v} \text {-surf }}$ & 2.78 & $\mathrm{DFT}+(\mathrm{U}=3.5)$ & This work \\
\hline $\mathrm{O}_{\mathrm{v} \text {-surf }}$ & 2.32 & $\mathrm{DFT}+(\mathrm{U}=3.0)$ & {$[15]$} \\
\hline $\mathrm{O}_{\mathrm{v} \text {-surf }}$ & 2.10 & $\mathrm{DFT}+(\mathrm{U}=3.0)$ & {$[28]$} \\
\hline $\mathrm{O}_{\mathrm{v} \text {-surf }}$ & 1.58 & $\mathrm{DFT}+\mathrm{D}$ & {$[28]$} \\
\hline $\mathrm{O}_{\mathrm{v} \text {-surf }}$ & 2.59 & $\mathrm{DFT}+(\mathrm{U}=3.0)$ & {$[44]$} \\
\hline $\mathrm{O}_{\mathrm{v} \text {-surf }}$ & 2.80 & $\mathrm{DFT}+(\mathrm{U}=4.0)$ & {$[44]$} \\
\hline $\mathrm{O}_{\mathrm{v} \text {-surf }}$ & 3.15 & $\mathrm{HSE06}$ & {$[45]$} \\
\hline
\end{tabular}

As shown in Fig. 6, compared with the perfect surface, the surface with OV exhibits a defective state at 0.8-1.0 eV below the conduction band, which is consistent with the previously reported results $[12,46]$. The removal of neutral oxygen atoms to form OV can lead to the redistribution of excess electrons between adjacent $\mathrm{Ti}$ atoms near the OV site, thus to the formation of shallow donor impurity levels below the conduction band of $\mathrm{Ti} 3 \mathrm{~d}$ orbitals, and the number of impurity levels increase with the increase of OV [47]. As a result, anatase $\mathrm{TiO}_{2}$ (101) shows the characteristics of n-type semiconductor. In this case, the band gap increases by $0.1-0.3 \mathrm{eV}$, which is consistent with bulk $\mathrm{TiO}_{2}$ [48-50]. The existence of the defect state is equivalent to building a step between $\mathrm{VB}$ and $\mathrm{CB}$, so that electrons can gradually transit from VB to $\mathrm{CB}$. For anatase $\mathrm{TiO}_{2}$ (101) surfaces with monolayer OV concentration of $1 / 8,2 / 8$, and $3 / 8 \mathrm{ML}$, the 
maximum transition energy between different energy levels is $1.888,1.888$, and $1.901 \mathrm{eV}$, respectively. Electron transitions on defect surfaces are easier than on prefect surface. By comparing the surfaces with different OV concentration, it is found that the maximum transition energy of the surfaces with three oxygen vacancies is the greatest. As mentioned earlier, this is caused by the relative weakening of the charge density of Ti atoms next to the OVs. This shows that moderate OV concentration can improve the electron transition ability, but an excessively high OV concentration may lead to the weakening of this enhancement effect.

The PDOS of anatase $\mathrm{TiO}_{2}$ (101) surface with different OV concentration is shown in Fig. 7. Pure anatase $\mathrm{TiO}_{2}$ (101) conduction band is mainly composed of $\mathrm{Ti} 3 \mathrm{~d}$ orbitals, while the valence band is mainly composed of $02 p$ orbitals, and the Fermi level is close to the top of the valence band. By comparing the density of states between a perfect surface and a surface with OVs, it is clear that the OV makes the Fermi level move into the bottom of the conduction band, and the surface structure presents the characteristics of n-type semiconductor. After the introduction of oxygen vacancy onto the surface, the total density of states of the system shifts to a lower energy level. Moreover, as the OV concentration increases, the total density of states shifts to an even lower energy level, and the Fermi energy level moves further into the conduction band. From the band gap, it can be found that the defect state is caused by OVs, and mainly contributed on Ti $3 \mathrm{~d}$. Most of the excess electrons are localized on Ti atoms, consistent with the results obtained from Table 2 analysis.

\subsubsection{Optical properties}

As can be seen from Fig. 8a, the light absorption curves of the anatase $\mathrm{TiO}_{2}(101)$ surface system with OVs exhibit blue shift to a certain extent, which is mainly due to the existence of OVs and the widening of the band gap of the system. The introduction of OVs improves the light absorption performance of anatase $\mathrm{TiO}_{2}$ (101), which is mainly reflected in the obvious increase in the visible light $(500-780 \mathrm{~nm})$ range, and in the significant in crease in the relative light absorption coefficient. The electron at the top of valence band is first excited to the impurity level, and then absorbs a photon with smaller energy to achieve indirect transition. More information can be obtained by analyzing the dielectric function. It can be seen from Fig. $8 \mathrm{~b}$ that an obvious peak of dielectric function appears for the defect surface in the range of $0-2.80 \mathrm{eV}$, but it does not appear for perfect anatase $\mathrm{TiO}_{2}(101)$, indicating that the peak is induced by OV on the surface. In the range of $2.80-4.80 \mathrm{eV}$, the dielectric peaks of the defect surface and perfect surface are roughly the same in shape, but slightly different in peak strength, indicating that the existence of OV has great influence on the energy band structure near the band gap. It can be also seen from Fig. $8 \mathrm{~b}$ that the imaginary part $\varepsilon_{2}$ of the dielectric function of defect anatase $\mathrm{TiO}_{2}$ (101) surface shifts to higher energy to varying degree. Its light wave absorption threshold produces a blue shift, which is consistent with the results obtained from the light absorption spectra.

The light absorption properties of the samples at different annealing temperatures and the corresponding band gap plots were obtained experimentally study, as shown in Fig. 9. Compared with $\mathrm{TiO}_{2}$-Air, black 
$\mathrm{TiO}_{2}$ nanotube arrays show stronger absorption in the visible region, as shown in Fig. 9a, which is consistent with the calculation results. It can be seen from the indirect interband transition energies that when the temperature reaches $600{ }^{\circ} \mathrm{C}$, the band gap increases from 2.81 to $2.90 \mathrm{eV}$. This finding indicates that when the OV concentration is too high, the enhancement effect of OV on the performance of $\mathrm{TiO}_{2}$ is weakened, which is in line with the conclusion of the previous band discussion.

\section{3 $\mathrm{H}_{2} \mathrm{O}$ adsorption and decomposition on anatase $\mathrm{TiO}_{2}$ (101) surface with $\mathrm{OV}_{\mathrm{S}}$}

In order to examine the adsorption and dissociation process of $\mathrm{H}_{2} \mathrm{O}$ on the surface of $\mathrm{TiO}_{2}$ (101) with different $\mathrm{OV}$ concentrations, the same number of $\mathrm{H}_{2} \mathrm{O}$ molecules are adsorbed on different surfaces to analyze the effect of OV concentration on hydrolysis by calculating the dissociation transition state. Previous studies $[15,18,51,52]$ found that the most stable adsorption configuration for water on the surface of pure anatase $\mathrm{TiO}_{2}(101)$ is to bond with the $\mathrm{Ti}_{5 \mathrm{c}}$ atom and form weak hydrogen bonds with two adjacent $\mathrm{O}_{2 \mathrm{c}}$ atoms. The most stable dissociation configuration is the formation of an $\mathrm{O}-\mathrm{H}$ bond between a $\mathrm{H}$ atom of water and an adjacent $\mathrm{O}_{2 \mathrm{c}}$ atom (bridged $\mathrm{OH}_{\mathrm{b}}$ ), and of a band between the remaining hydroxyl $\mathrm{OH}$ with the surface $\mathrm{Ti}_{5 \mathrm{c}}$ atom through the $\mathrm{O}$ atom (terminal hydroxyl $\mathrm{OH}_{\mathrm{t}}$ ). In previous reports [27,53], it was also found that the most stable adsorption site of water on defect anatase $\mathrm{TiO}_{2}$ (101) surface is the vacancy site at the $\mathrm{OV}$, where the $\mathrm{O}$ atom of water molecule almost occupies the position of "bridged $\mathrm{O}_{2 \mathrm{c}}$ atom" in the vacancy, one hydrogen atom points to the adjacent bridged $\mathrm{O}_{2 \mathrm{c}}$ atom, and the other hydrogen atom points far away from the surface. In the corresponding dissociating adsorption state, the decomposed product oxygen atom becomes the bridged $\mathrm{O}_{2 \mathrm{c}}$ atom of surface, and bonds with one of the hydrogen atoms to form surface-terminated hydroxyl radical, while the other hydrogen atom is adsorbed onto adjacent bridged $\mathrm{O}_{2 \mathrm{c}}$ atom to form another surface-terminated hydroxyl radical. On the basis of existing research conclusions, a possible stable configuration of water adsorption on the surface is constructed and optimized, and the adsorption energy is obtained. The calculated adsorption configuration and adsorption energy are basically identical with previous studies $[36,53]$.

As shown in Fig. 10a, the most stable adsorption configuration for water on the surface of perfect anatase $\mathrm{TiO}_{2}$ (101) is to combine with one $\mathrm{Ti}_{5 \mathrm{c}}$ atom and form weak hydrogen bonds with two adjacent $\mathrm{O}_{2 \mathrm{c}}$ atoms. In this state, the adsorption energy is $0.693 \mathrm{eV}$. The most stable dissociation configuration is that a hydrogen atom of water forms an $-\mathrm{OH}$ bond with adjacent $\mathrm{O}_{2 \mathrm{c}}$ atom, and the remaining hydroxyl $(-\mathrm{OH})$ bonds with the surface $\mathrm{Ti}_{5 \mathrm{c}}$ atom through the oxygen atom. In this state, the adsorption energy is $0.400 \mathrm{eV}$. The process is endothermic. The adsorption energy of the transition state of the reaction is $0.026 \mathrm{eV}$. From the initial adsorbed molecular state, $\mathrm{a}_{2} \mathrm{O}$ molecule requires an overall activation energy of $0.719 \mathrm{eV}$ to decompose, while the activation energy for its reverse reaction is $0.426 \mathrm{eV}$. So the dissociation is more difficult, and $\mathrm{H}_{2} \mathrm{O}$ is more likely to undergo molecular adsorption. As shown in 
Fig. $10 \mathrm{~b}-\mathrm{d}, \mathrm{a} \mathrm{H} \mathrm{H}_{2} \mathrm{O}$ molecule is adsorbed at the same positions on the surfaces of anatase $\mathrm{TiO}_{2}(101)$ with OV concentration of $1 / 8,2 / 8$ and $3 / 8 \mathrm{ML}$, separately. The most stable adsorption configuration is obtained by optimizing the adsorption model. The $\mathrm{O}$ atom of $\mathrm{H}_{2} \mathrm{O}$ almost occupies the position of the bridged $\mathrm{O}_{2 \mathrm{c}}$ atom at the vacancy, one hydrogen atom points to adjacent bridged $\mathrm{O}_{2 \mathrm{c}}$ atom, and the other points away from the surface. By analyzing the transition states of water molecule dissociating on different surfaces, it is found that on the surface with OV concentration of $1 / 8 \mathrm{ML}, \mathrm{H}_{2} \mathrm{O}$ molecule needs to absorb an energy of $1.183 \mathrm{eV}$ to reach the transition state, while the reverse reaction activation energy is $1.837 \mathrm{eV}$. On the surface with OV concentration of $2 / 8 \mathrm{ML}, \mathrm{H}_{2} \mathrm{O}$ molecule needs to absorb an energy of $1.315 \mathrm{eV}$ to reach the transition state, while the reverse reaction activation energy is $1.692 \mathrm{eV}$. On the surface with $\mathrm{OV}$ concentration of $3 / 8 \mathrm{ML}, \mathrm{H}_{2} \mathrm{O}$ molecule needs to absorb an energy of $1.545 \mathrm{eV}$ to reach the transition state, while the reverse reaction activation energy is $2.057 \mathrm{eV}$. The overall water splitting reaction that occurs on the defect surface is exothermic, and the activation energy of the reverse reaction is much greater than that of the forward reaction, that is, the reaction more likely proceeds in the direction of dissociation. From the comparison of the water splitting reaction on the surface with OV concentration of $1 / 8$ and $2 / 8 \mathrm{ML}$, the dissociation energy barrier of water molecule on the latter is increased by 0.132 $\mathrm{eV}$, indicating that water splitting is more likely to occur on the former. On the other hand, the activation energy of the reverse reaction on the latter is $0.151 \mathrm{eV}$ lower than that on the former, indicating that the water splitting products on the former are more stably adsorbed on the catalyst surface. When the OV concentration reaches $3 / 8 \mathrm{ML}$, the forward reaction barrier of water splitting reaction reaches $1.545 \mathrm{eV}$, and the reaction is more difficult to proceed. Figure 11 shows the dependence of the activation energy of the decomposition reaction $\left(E_{\mathrm{act}}\right)$ and the activation energy of the reverse reaction $\left(E_{\mathrm{re}-\mathrm{act}}\right)$ on $\mathrm{OV}$ concentration. Consequently, the anatase (101) surface with OV concentration of $1 / 8 \mathrm{ML}$ is more conducive to the water splitting reaction. From this point of view, the presence of OVs can indeed promote the progress of water splitting reaction, but as the concentration gets higher, its promotion effect weakens.

\subsection{Photocatalytical hydrogen evolution performance}

In order to verify the accuracy of computational results, the photocatalytical hydrogen production of anatase $\mathrm{TiO}_{2}$ was experimentally conducted. In Fig. 12, the photocatalytical hydrogen production performance of $\mathrm{TiO}_{2}$-NTAs treated at different temperatures is compared. Obviously, the hydrogen production performance of the black $\mathrm{TiO}_{2}$ nanotube arrays obtained by the reduction of aluminum powder is significantly higher than that of control sample, indicating that OV can indeed improve the hydrogen production performance of the catalyst. There is a relatively large improvement in hydrogen production performance from $300^{\circ} \mathrm{C}$ to $450^{\circ} \mathrm{C}$, but when the annealing temperature is further raised to $600^{\circ} \mathrm{C}$, the improvement in hydrogen production performance is very weak. There is a flattening trend in the promotion of the photocatalytic reaction as OV concentration increases. These results prove that the calculation results are accurate. 


\section{Conclusion}

In this work, the effect of oxygen vacancy concentration was investigated on the crystalline phase, electronic structure, and catalytic activity of $\mathrm{TiO}_{2}$ through DFT calculations and experiments. The comparison between the measured XRD patterns of $\mathrm{TiO}_{2}$ catalysts and the simulated XRD patterns of $\mathrm{TiO}_{2}$ crystals validated the assumption that OVs cause change in the crystal structure and catalytic activity of $\mathrm{TiO}_{2}$. The changes in the electronic structure of anatase $\mathrm{TiO}_{2}(101)$ as a function of OV concentration indicate that moderate $\mathrm{OV}$ concentration can improve the transition ability of electrons, but excessively high OV concentration may weaken this increase. In addition, the presence of oxygen vacancy does promote the progress of water spliting reaction, but as the concentration becomes higher, its promotion effect will be weakened. The modification of the electronic structure of anatase $\mathrm{TiO}_{2}(101)$ with OVs is attributed mainly to the structure distortion and the electron transfer from OVs to Ti atoms, which leads to subsequent introduction of extra donor levels at the bottom of $\mathrm{CB}$. Therefore, the electronic structure and catalytic performance of anatase $\mathrm{TiO}_{2}$ can be effectively modulated by adjusting surface OV concentration.

\section{Declarations}

\section{Acknowledgments}

This work was supported by the Natural Science Foundation of China [62004137, 21878257; 21978196]; Natural Science Foundation of Shanxi Province [201701D221083]; Key Research and Development Program of Shanxi Province [201803D421079]; Scientific and Technological Innovation Programs of Higher Education Institutions in Shanxi [2019L0156]; Shanxi Provincial Key Innovative Research Team in Science and Technology [201605D131045-10]; and Research Project Supported by Shanxi Scholarship Council of China [2020-050].

\section{Compliance with ethical standards}

Conflict of interest No conflict of interest exists in the submission of this manuscript, and manuscript is approved by all authors for publication.

\section{References}

1. W.J. Ong, L.L. Tan, S.P. Chai, S.T. Yong, A.R. Mohamed, ChemSusChem. 7, 690-719 (2014)

2. A. Fujishima, K. Honda, Nature. 238, 37-38 (1972)

3. X. Chen, S. Shen, L. Guo, S.S. Mao, Chem. Rev. 110, 6503-6570 (2010)

4. L. Yoong, F.K. Chong, B.K. Dutta, Energy. 34, 1652-1661 (2009)

5. K. Hashimoto, H. Irie, A. Fujishima, Jpn. J. Appl. Phys. 44, 8269-8285 (2005)

6. Q. Guo, C. Zhou, Z. Ma, X.M. Yang, Adv. Mater. 31, 1901997 (2019) 
7. X. Chen, S.S. Mao, Chem. Rev. 107, 2891-2959 (2007)

8. B. Lahijani, K. Hedayati, M. Goodarzi, Main Group Met. Chem. 41, 53-62 (2018)

9. Z. Ebrahimi, K. Hedayati, D. Ghanbari, J. Mater. Sci. Mater. Electron. 28, 13956-13969 (2017)

10. K. Su, Z. Ai, L. Zhang, Phys. Chem. C 116, 17118-17123 (2012)

11. Y.C. Zhang, N. Afzal, L. Pan, X.W. Zhang, J.J. Zou, Adv. Sci. 6, 1900053 (2019)

12. G. Zhu, T. Lin, X. Lu, J. Mater. Chem. A 1, 9650-9653 (2013)

13. I. Justicia, G. Garcia, L. Vazquez, J. Santiso, P. Ordejon, G. Battiston, R. Gerbasi, A. Figuerasa, Sensor Actuat. B-Chem. 109, 52-56 (2005)

14. X.B. Chen, L. Liu, P.Y. Yu, S.S. Mao, Science 331, 746-750 (2011)

15. F. Zuo, L. Wang, T. Wu, Z.Y. Zhang, D. Borchardt, P.Y. Feng, J. Am. Chem. Soc. 132, 11856-11857 (2010)

16. J.Q. Gao, Q.Q. Shen, R.F. Guan, J.B. Xue, X.G. Liu, H.S. Jia, Q. Li, Y.C. Wu, J. $\mathrm{CO}_{2}$ Util. 35, 205-215 (2020)

17. T.L. Thompson, J.T. Yates, Top. Catal. 35, 197-210 (2005)

18. Y. Hinuma, T. Toyao, T. Kamachi, Z. Maeno, S. Takakusagi, S. Furukawa, I. Takigawa, K. Shimizu, J. Phys. Chem. C 122, 29435-29444 (2018)

19. M. Kong, Y. Li, X. Chen, T. Tian, P. Fang, F. Zheng, X.J. Zhao, Am. Chem. Soc. 133, 16414-16417 (2011)

20. S.Q. Wei, F. Wang, M. Dan, K.Y. Zeng, Y. Zhou, Appl. Surf. Sci. 422, 990-996 (2017)

21. H. Shi, Y.C. Liu, M. Miao, T. Wu, Q. Wang, Chem. Phys. Lett. 584, 98-102 (2013)

22. D. Wang, H. Wang, P. Hu, Phys. Chem. Chem. Phys. 17, 1549-1555 (2014)

23. D. Wang, T. Sheng, J.F. Chen, H.F. Wang, P. Hu, Nat. Catal. 1, 291-299 (2018)

24. A. Barnard, P. Zapol, L. Curtiss, Surf. Sci. 582, 173-188 (2005)

25. P. Maity, O.F. Mohammed, K. Katsiev, H. Idriss, J. Phys. Chem. C 122, 8925-8932 (2018)

26. I.M. Nadeem, G.T. Harrison, A. Wilson, C.L. Pang, J. Phys. Chem. B 2, 834-839 (2018)

27. J.P. Perdew, K. Burke, M. Ernzerhof, Phys. Rev. Lett. 77, 1396-1396 (1997)

28. M.A. Ha, A.N. Alexandrova, J. Chem. Theory. Comput. 12, 2889-2895 (2016)

29. J.Y. Liu, X.Q. Gong, A.N. Alexandrova, J. Phys. Chem. C 123, 3505-3511 (2019)

30. C. Dette, M.A. Perez-Osorio, S. Mangel, F. Giustino, S.J. Jung, K. Kern, J. Phys. Chem. C 121, 11821187 (2017)

31. W.Q. Chen, C. Tang, G. Zheng, Phys. B 404, 1074-1078 (2009)

32. M. Arrigoni, G.K.H. Madsen, J. Chem. Phys. 152, 044110 (2020)

33. G. Shukri, W.A. Dino, H.K. Dipojono, M.K. Agusta, H. Kasai, RSC Adv. 6, 92241-92251 (2016)

34. U. Aschauer, Y. He, H. Cheng, S.C. Li, U. Diebold, A. Selloni, J. Phys. Chem. C 114, 1278-1284 (2010) 35. W.J. Yin, B. Wen, Q.X. Ge, X.L. Wei, M.Y. Chen, L.M. Liu, Comp. Mater. Sci. 155, 424-430 (2018) 
36. Y. Cao, L. Ling, H. Lin, M.H. Fan, P. Liu, R.G. Zhang, B.J. Wang, Comp. Mater. Sci. 159, 1-11 (2019) 37. U. Aschauer, Y. He, H. Cheng, S.C. Li, U. Diebold, A. Selloni, J. Phys. Chem. C 114, 1278-1284 (2010) 38. R.G. Zhang, Z.X. Liu, L.X. Ling, B.J. Wang, Appl. Surf. Sci. 353, 50-157 (2015) 39. M.T. Greiner, L. Chai, M.G. Helander, W.M. Tang, Z.H. Lu, Adv. Funct. Mater. 22, 4557-4568 (2012) 40. S.T. Li, S.R. Shi, G.C. Huang, Y. Xiong, S.W. Liu, Appl. Surf. Sci. 455, 1137-1149 (2018) 41. X. Li, S. Liu, K. Fan, Z.Q. Liu, B. Song, J.G. Yu, Adv. Energy Mater. 8, 1800101 (2018) 42. Y. Wu, Y. Fu, L. Zhang, Y.H. Ren, X.Y. Chen, B. Yue, H.Y. He, Chinese J. Chem. 37, 922-928 (2019) 43. M.H. Oza1, D.K. Kanchan, J.H. Joshi, M.J. Joshi, J. Mater. Sci. Mater. Electron. 31, 10177-10185 (2020)

44. Y.N. Hao, T.W. Chen, X. Zhang, H. Zhou, Y.C. Ma, J. Chem. Phys. 150, 224702 (2019)

45. L. Kou, Th Frauenheim, A.L. Rosa, E.N. Lima, J. Phys. Chem. C 121, 17417-17420 (2017)

46. Y. Nam, J.H. Lim, K.C. Ko, J.Y. Lee, J. Mater. Chem. A 7, 13833-13859 (2019)

47. X. Pan, M.Q. Yang, X. Fu, N. Zhang, Y.J. Xu, Nanoscale 5, 601-3614 (2013)

48. M. Elahifard, H. Heydari, R. Behjatmanesh-Ardakani, B. Peik, S. Ahmadvand, J. Phys. Chem. Solids 136, 109176 (2019)

49. Z. Zhou, M. Li, L. Guo, J. Phys. Chem. Solids 71, 1707-1712 (2010)

50. G.U. Oertzen, A.R. Gerson, J. Phys. Chem. Solids 68, 324 - 330 (2007)

51. Y.B. He, A. Tilocca, O. Dulub, A. Selloni, U. Diebold, Nat. Mater. 8, 585-589 (2009)

52. G. Fisicaro, S. Filice, S. Scalese, G. Compagnini, R. Reitano, L. Genovese, S. Goedecker, I. Deretzis, A. La Magna, J. Phys. Chem. C 124, 2406-2419 (2020)

53. Z.Y. Zhao, Z.S. Li, Z.G. Zou, J. Phys. Chem. C 117, 6172-6184 (2013)

\section{Figures}




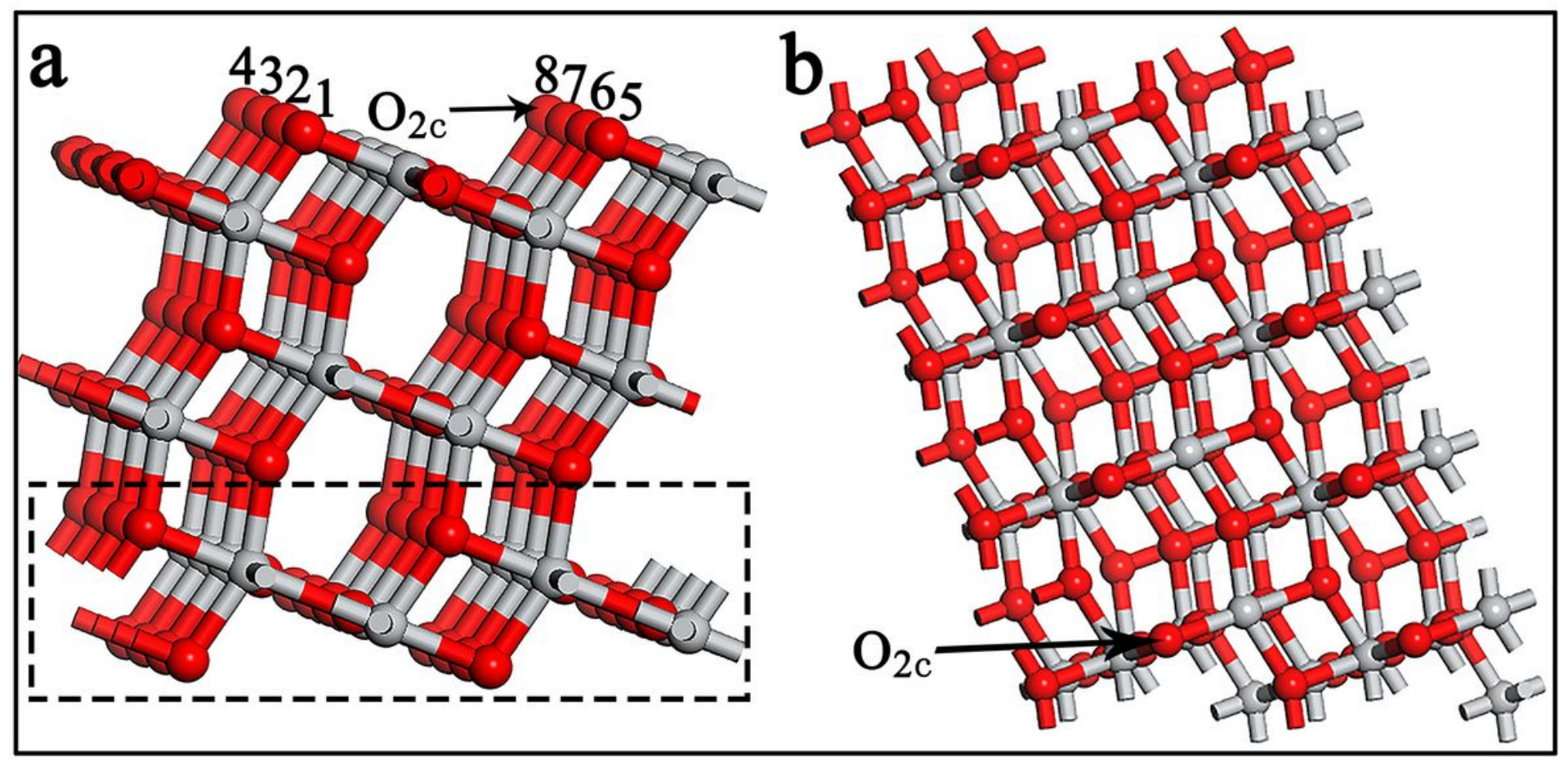

Figure 1

Side view (a) and top view (b) of perfect anatase TiO2 (101) surface supercell constructed by $(4 \times 1)$ surface unit-cells

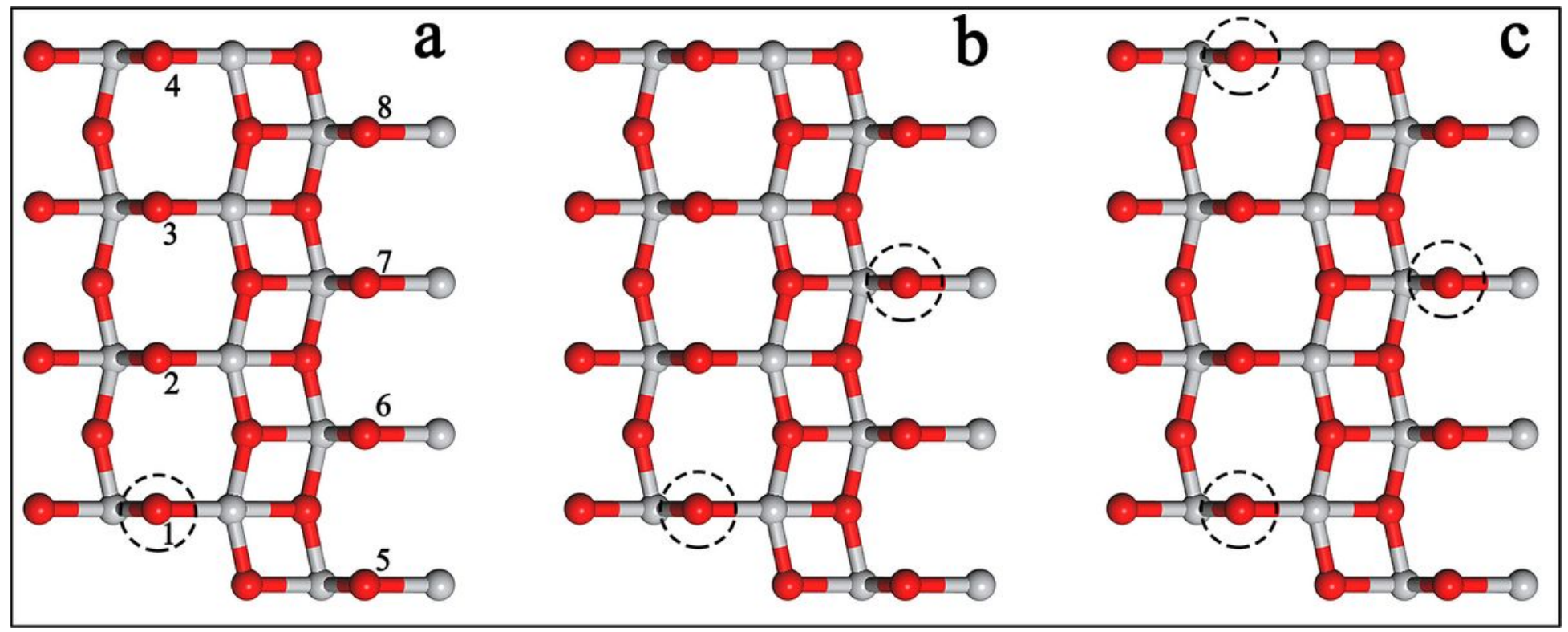

Figure 2

Top views of anatase TiO2 (101) surfaces with 1/8 (a), 2/8 (b), and 3/8(c) ML OVs, respectively 

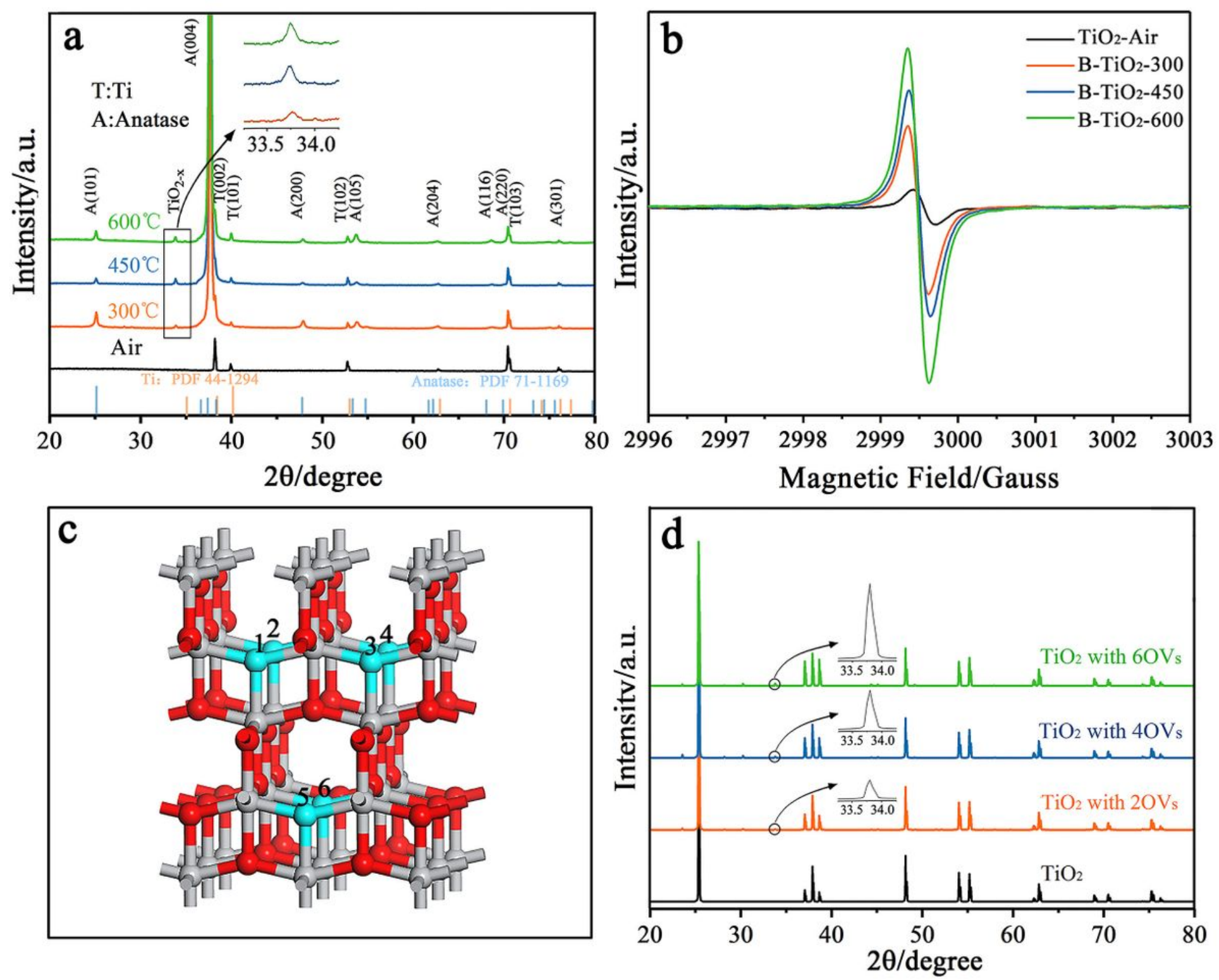

Figure 3

(a) Measured XRD patterns of TiO2; (b) EPR spectra of black TiO2 nanotube arrays; (c) TiO2 $(2 \times 2 \times 1)$ supercell model with a different number of OVs; and (d) simulated XRD patterns of TiO2 crystals with different numbers of OVs 


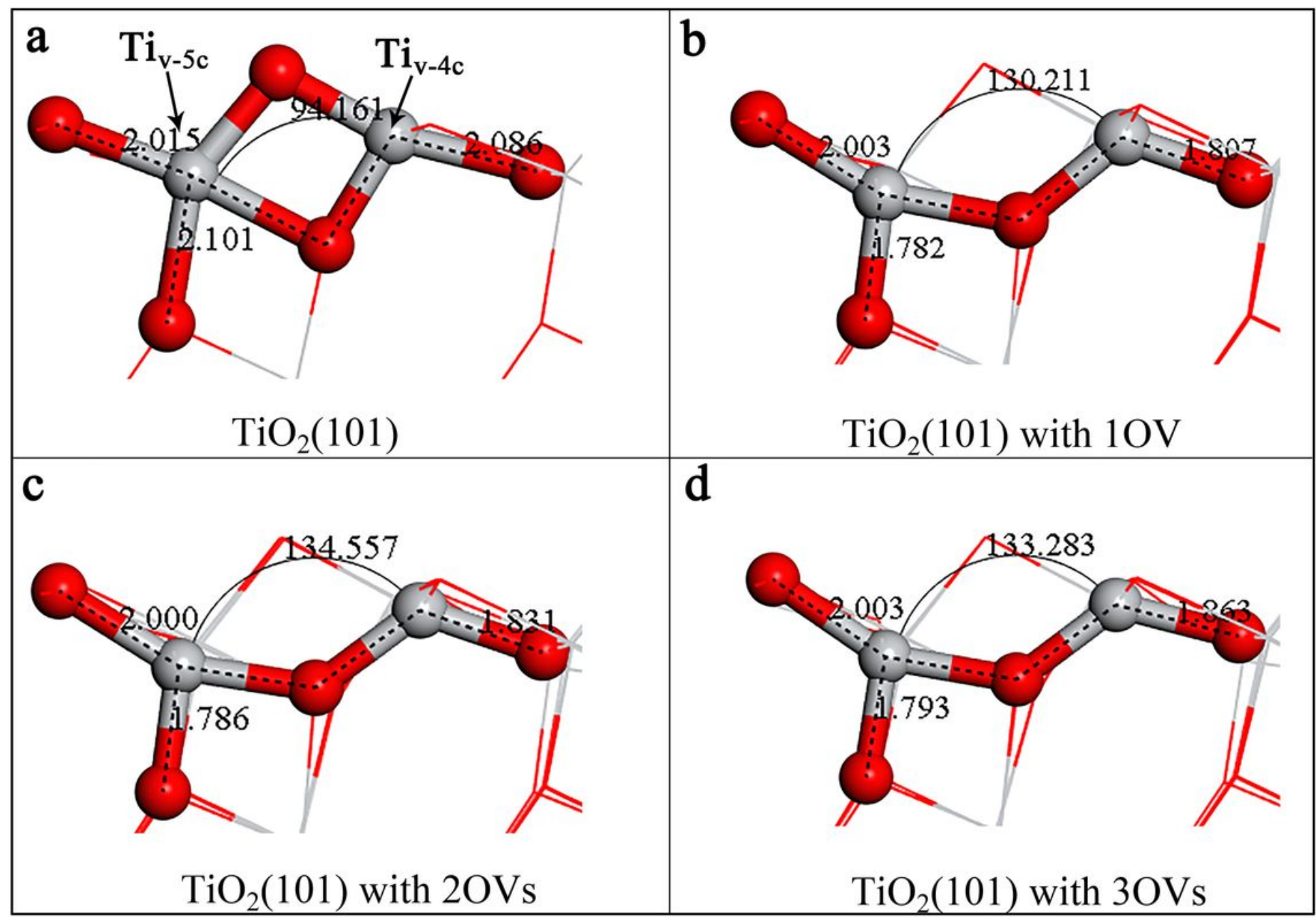

Figure 4

Local geometric structure of anatase TiO2 (101) surfaces with 0 (a), 1/8 (b), 2/8 (c), and $3 / 8$ (d) ML OVs, respectively 


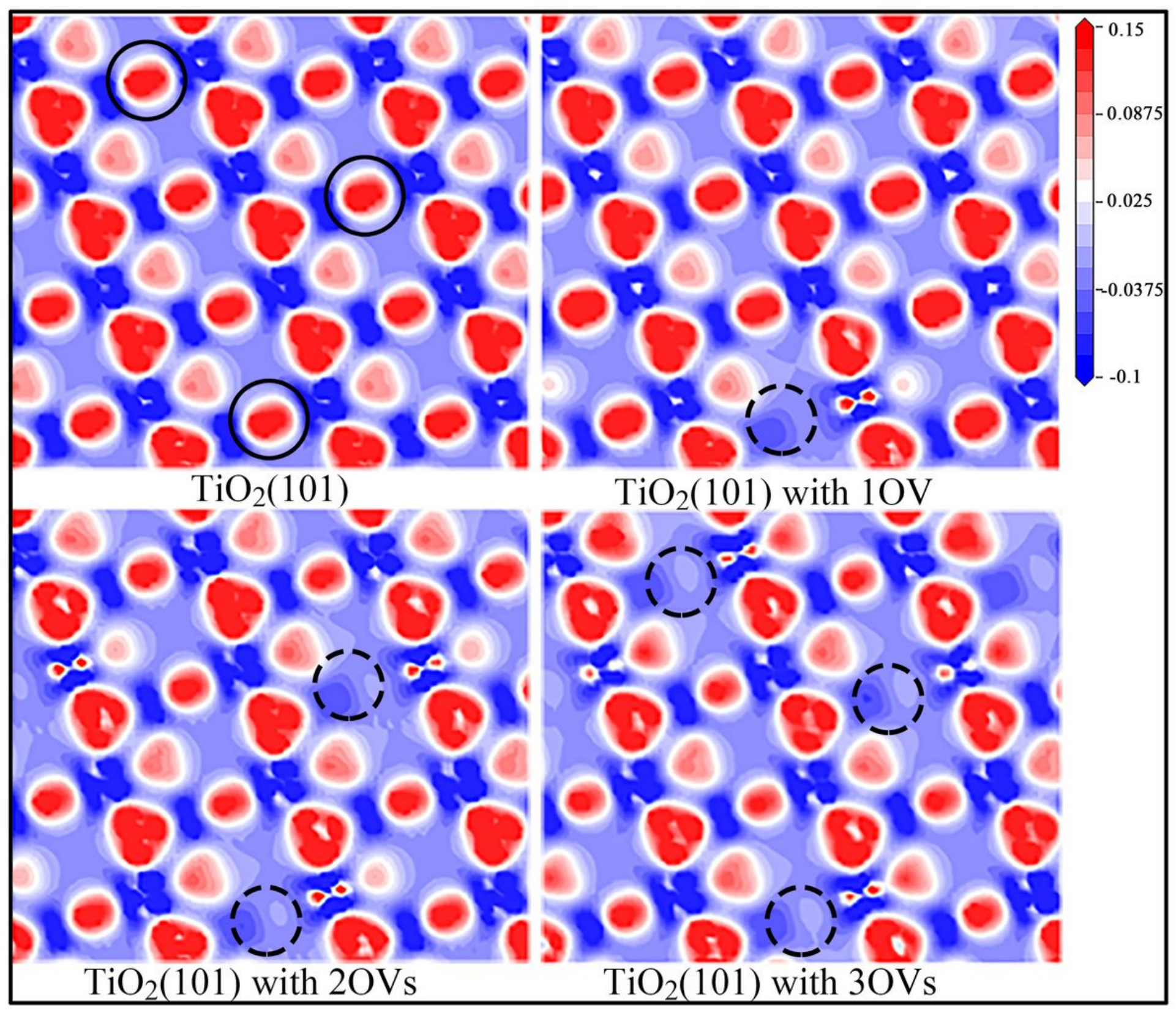

\section{Figure 5}

Density difference of anatase TiO2 (101) surfaces with 0 (a), 1/8 (b), 2/8 (c), and 3/8 (d) ML OVs, respectively. Red areas represent electron enrichment and blue areas electron deficiency 

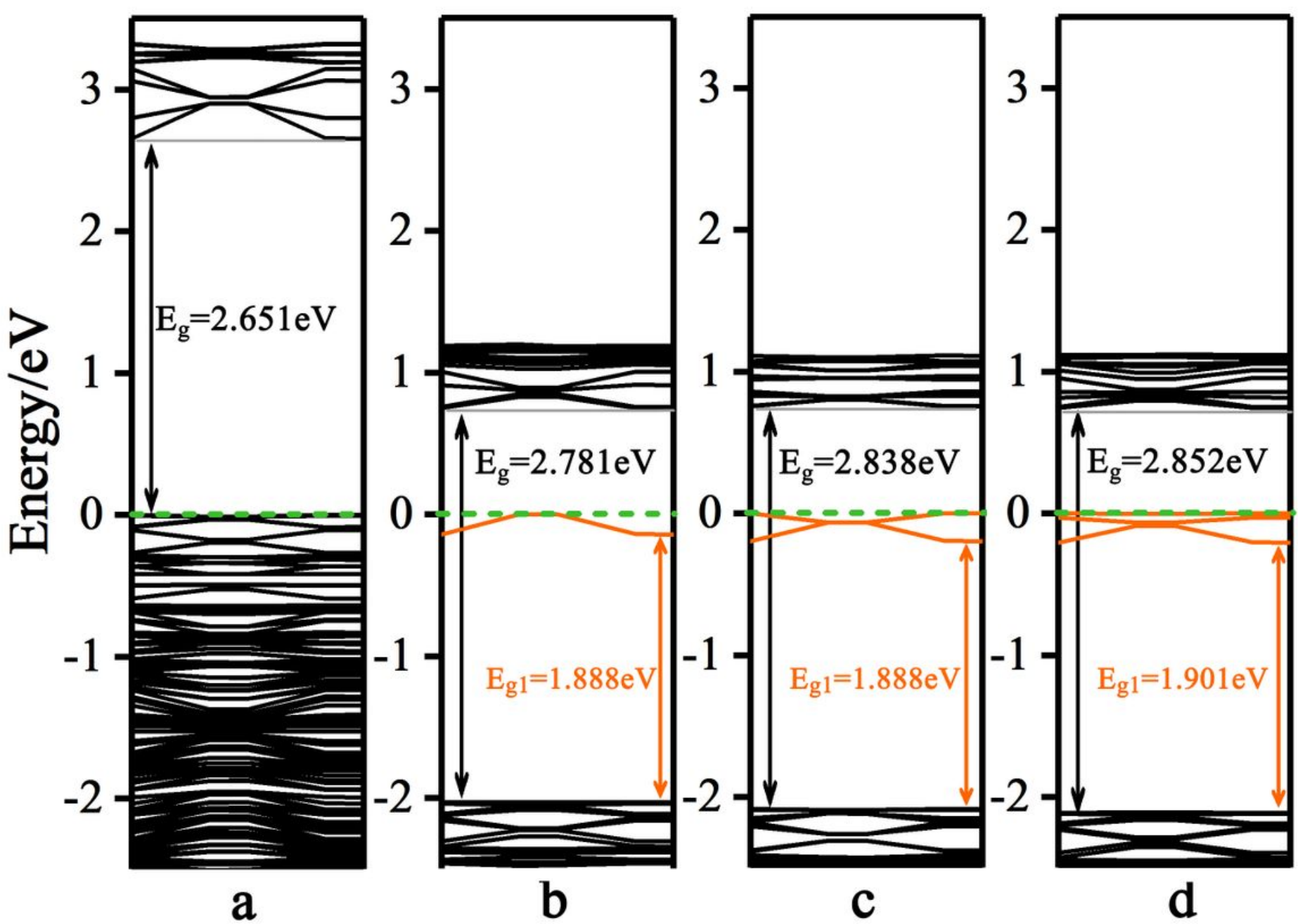

Figure 6

Band structures of anatase TiO2 (101) surfaces with 0 (a), 1/8 (b), 2/8 (c), and 3/8 (d) ML OVs, respectively. The Fermi level and defect levels are highlighted in green and orange, respectively 


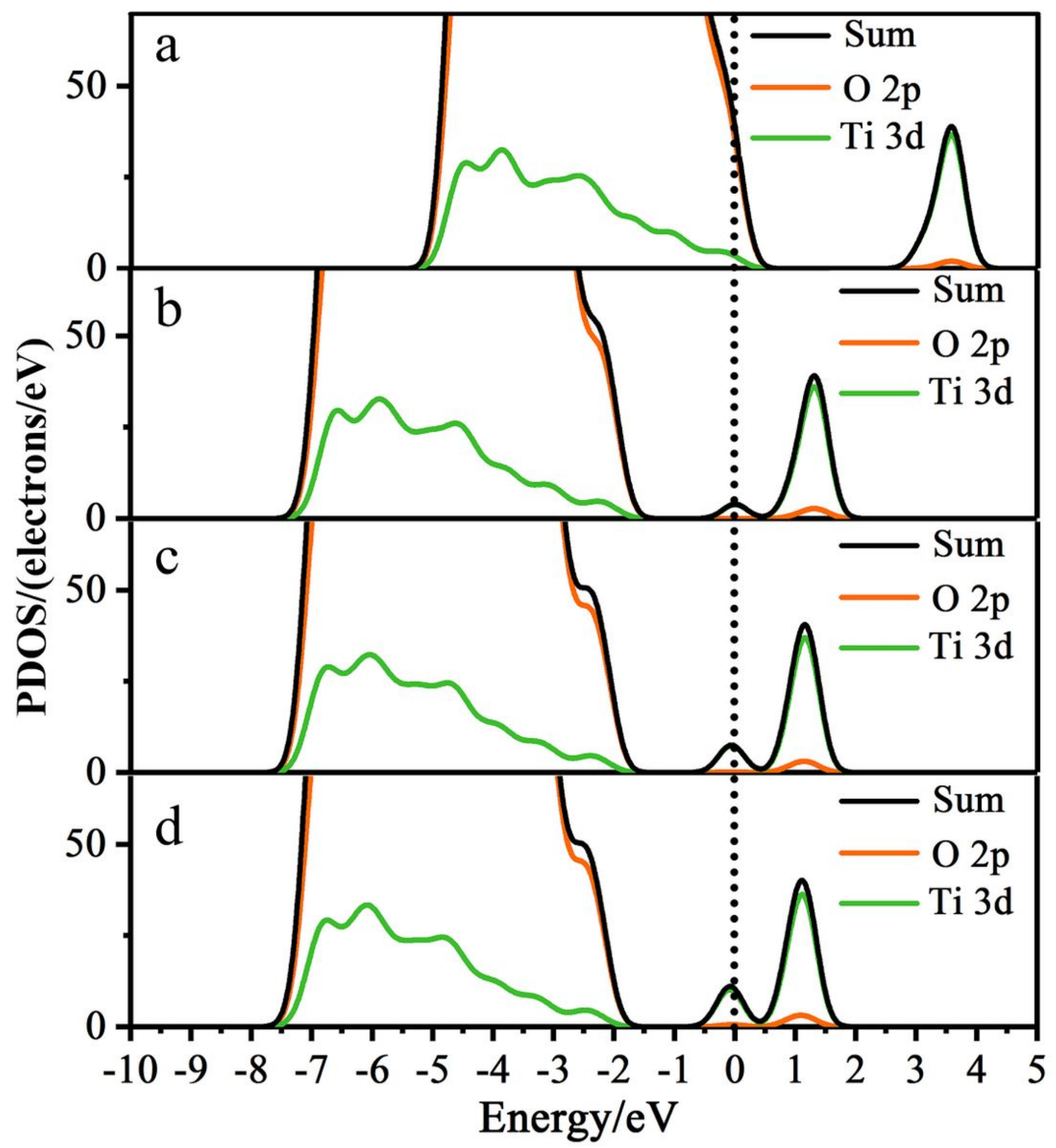

Figure 7

PDOS of anatase TiO2 (101) surfaces with 0 (a), 1/8 (b), 2/8 (c), and 3/8 (d) ML OVs, respectively 

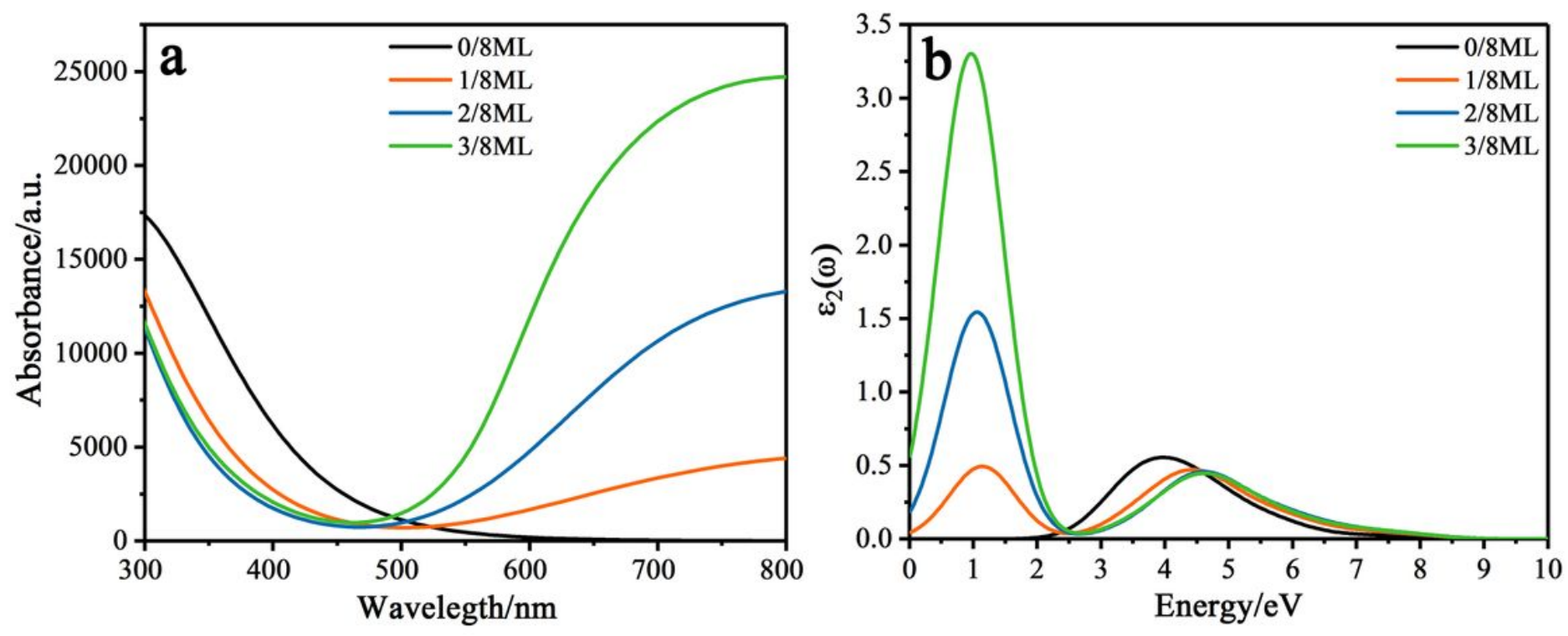

Figure 8

UV-vis absorption spectra (a) and dielectric function (b) of anatase TiO2 (101) with different concentration of OVs
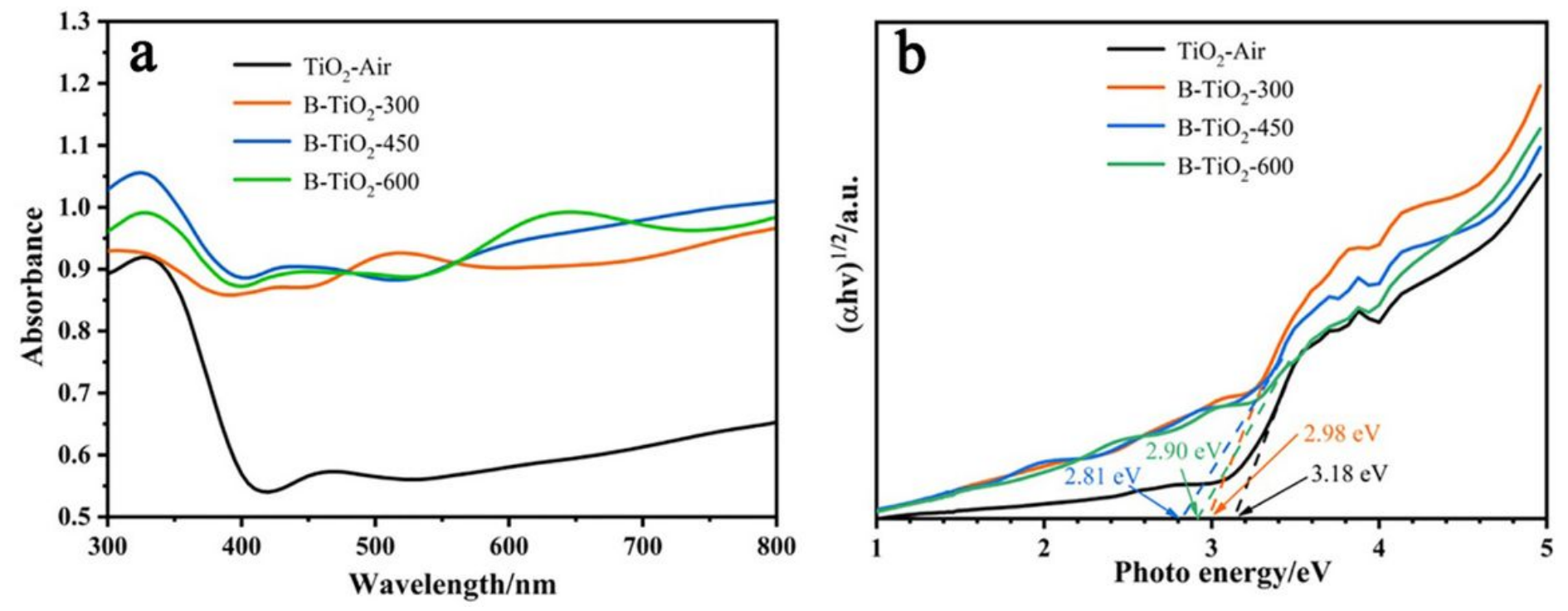

Figure 9

UV-vis diffuse reflectance absorption spectra (a) and determination of indirect interband transition energies (b) 


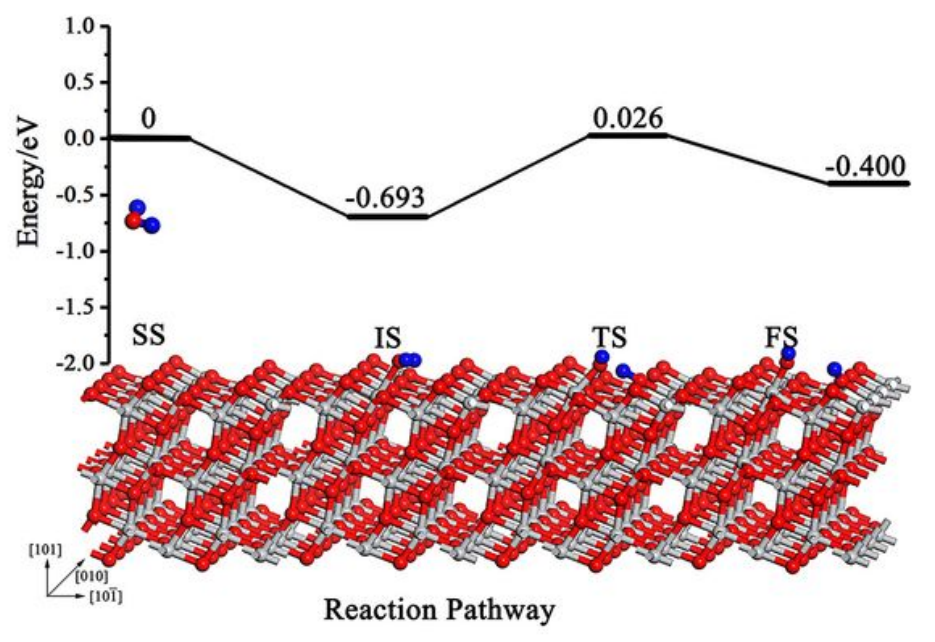

a

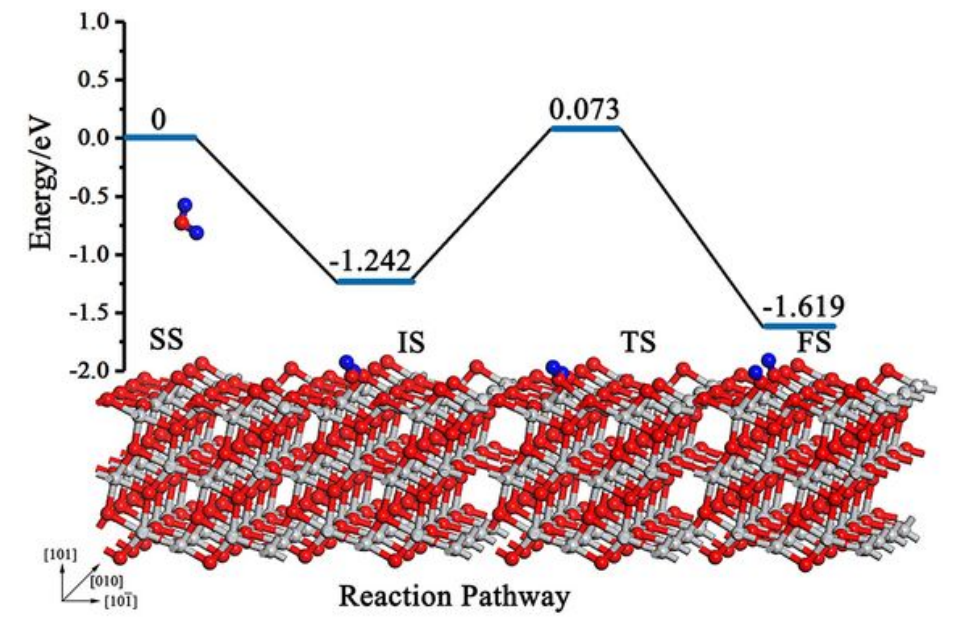

C

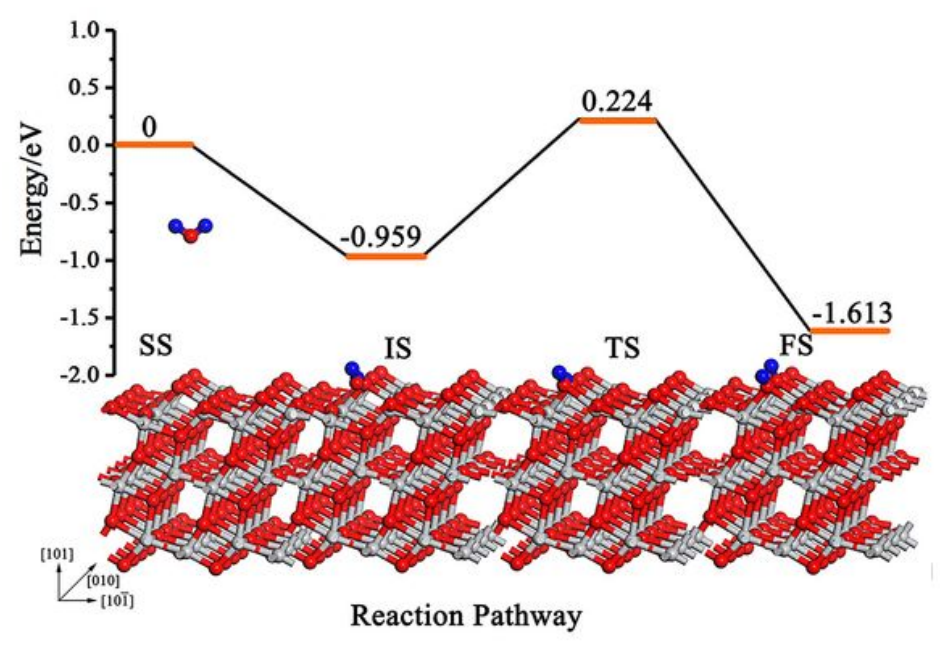

b

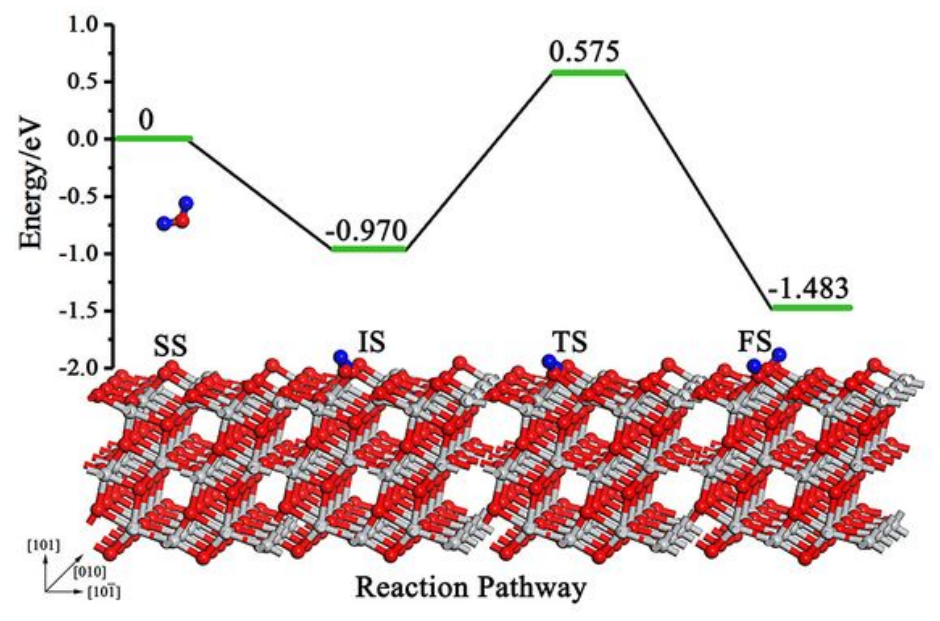

d

\section{Figure 10}

Adsorption configurations and decomposition reaction pathway of water on the anatase TiO2 (101) surface with 0 (a), 1/8 (b), 2/8 (c), and 3/8 (d) ML OVs, respectively. "SS" denotes the separate state, "IS" the initial state, "TS" the transition state, and "FS" the final state 


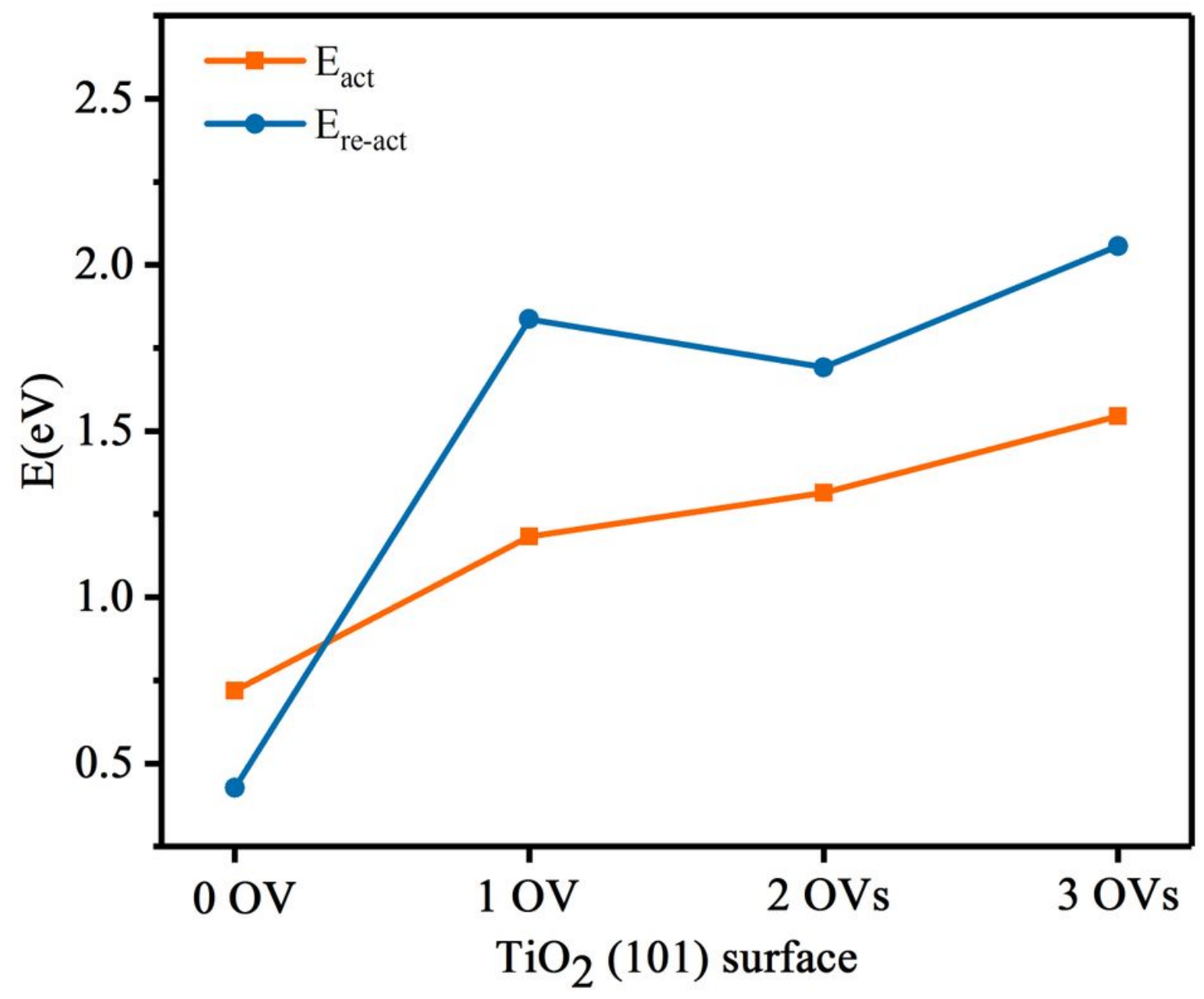

Figure 11

Change in the decomposition reaction activation energy (Eact) and the reverse reaction activation energy (Ere-act) as a function of OV concentration 


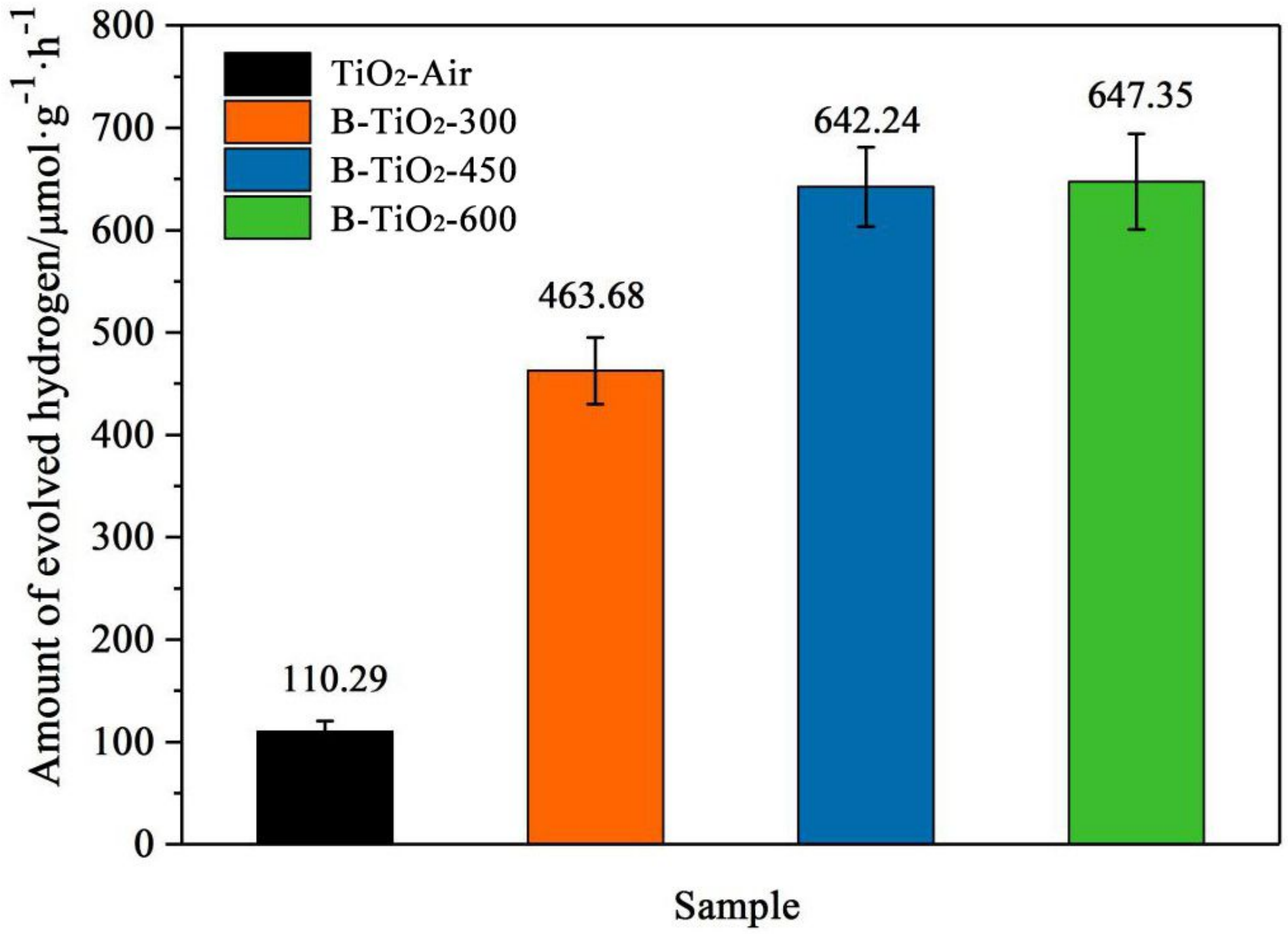

Figure 12

Comparison of photocatalytical hydrogen evolution rates 